\section{Inculcating reading habits among Nigerian secondary schools students: the role of libraries}

Information Impact: Journal of Information and Knowledge Management 2017, Vol. 8 (1) Pg 30 - 37 ISSN: $2141-4297$ (print) ISSN: 2360 - 994X (e-version) www.informationimpact.org

Gayus Yaji

Federal College of Education (Technical), Gombe

Hassan S. Dala

Federal College of Education (Technical), Gombe

Edward Danburam

Federal College of Education (Technical), Gombe

\begin{abstract}
This paper looks at reading habit as process of imbibing a culture of educating, informing and enlightening people. Inculcating reading habit is very essential for the academic achievement of children and this is made possible with the help of trained and qualified teachers who help in guiding children in developing the right attitudes and skills in reading. The paper also identifies the causes of poor reading habits in our society to include poor family environment and background, lack of functional schools and public libraries, inadequate equipment and information resources in schools, and insufficient and ineffective teachers to help the students. The paper also examines other countries that have made advancement in helping its citizens, particularly young people inculcate good reading habits and how Nigeria can learn from the experiences of those countries. The role of libraries in educating its citizens to imbibe good reading culture cannot be overemphasized. This is the only way its citizens can make advancement in their career and make meaningful contribution to the society. The paper concludes by making recommendations that all schools should have functional libraries and the local and state governments should also provide public library services in the nook and crannies of the state to make information accessible to people. This is in addition to having qualified and efficient teaching on reading culture in our secondary schools.
\end{abstract}

Keywords: reading habits, reading culture, students, children, Nigeria

\title{
Introduction
}

One of the most important ways of developing the youths to become important people in the society is through imbibing them with reading culture through the informative, creative and inspiring works of literature that enrich life experiences. People therefore often read for pleasure and relaxation, information, and for knowledge. Like any skill worth mastering, a reading habit requires time and dedication to develop. It is however a lifelong source of enjoyment and entertainment and an affordable hobby for anyone who wants to pick up a book and read. Palani (2012) explained that reading is the identification of the symbols and the association of the appropriate meaning with them. It requires identification and comprehension. Comprehension skills help the learner to understand the meaning of words in isolation and in context. Reading habit involves the mental process of interpretation of signs perceived through sense organs and it also means the ability to pronounce words that are written. The primary reason why we read is to obtain information as well as comprehend or understand a text. According to Green (2001) 
Reading habit is best formed at a young impressionable age in school, but once formed it can last one's life time. Therefore, reading is a skill that must be nurtured from a child's earliest years. Once children know how to read, they still need support to reach their full potential as readers.

In order to build strong reading habits and enjoy reading to the fullest, children should begin practicing good reading skills. For example, when you read, read the main idea of each paragraph along with its supporting reasons. Building up reading skills can be helpful to read with a pencil in hand to take notes or underline the key idea of each paragraph. Look up unfamiliar words, simply underline or make a list of unfamiliar words and later return to each word and look it up, re-reading the sentence it appeared. This helps contextualize the word and its usage in case there are multiple meanings. Learn to appreciate the context of the text can offer clues as to what the character or writer is talking about. This may require a small amount of outside research to become informed on the different levels of context presented by a text.

Comprehension is at the center of reading. Collins and Check (1999), described reading as a process that requires an ability to comprehend a thought unit in order to understand a printed message. According to Rubin (2002), reading is a total integrative process that starts with the reader and includes the affective, perceptual and cognitive domains. Okebukola (2004) affirmed that through reading, humans have the tools to transmit knowledge to each succeeding generation; it allows one to listen to the wisdom and people of the ages. Douglas (2002) further asserts that every child must become fully competent in reading to succeed in school and discharge his responsibility as a citizen of a democratic society. Reading is the foundation of much enjoyment in life and is closely related to vocational efficiency. Students must rely on written or digital word to convey information and data. The ability to read well is absolutely critical to success in life.

\section{Causes of Poor Reading Habits}

The decline in reading among children is an offshoot of technological advancements that have brought about overall changes in family's social and economic conditions. For example, poor reading habits occur in children and young people because reading is not considered a relevant leisure activity as it does not form part of children's social interaction, and reading is considered a solitary pursuit and is not attractive compared to interactive activity on the internet and watching television (Ajayi, 2012). This is because young people have the desire to spend more time with their friends than to remain at home reading. Children and young people tend to enjoy television and films as a way of enjoying their leisure instead of reading. This is coupled to the fact that there is an unprecedented rise in the prize of books while DVDs are becoming more affordable. Also, children with poor reading problems, seems to dislike school and often fail to develop their full potential. In their survey of the factors affecting the reading habits of secondary school students, Ogunrombi and Dio (1995) identified the following: 
$>$ The family background of students does not contribute to their reading habit as few homes have libraries. In addition adverse home factors like lack of support and encouragement to lack of facilities for reading at home. The traditional home is like a social market in which loneliness is discouraged, thus promoting noise which is distractive to reading.

There are no functional libraries in most of the schools nor are there trained librarians or teacher- librarians.

Equipment and resources for teaching reading skills are lacking, coupled with a dearth of language teachers.

> The authoritarian syndrome associated with African society negatively affects the reading habit of children by inhibiting the development of inquisitive attitudes.

Conditions in school environments include inefficient and ineffective methods for teaching and reading due to untrained teachers.

In his contribution, Rubin (2002) said that children with poor reading habits have a higher chance of anti-social behaviors such as delinquency, school violence, bullying, hacking computers and even examination malpractices. This does not mean that all those with poor reading habits display such behaviors, however, poor reading habits are associated with such behavioral patterns while good reading habits help develop a steady and constructive mind. Rubin therefore outlined poverty, corruption, noise culture, undue importance to wealth, lack of reading language, and dearth of libraries as the causes of poor reading habits.

In his contribution, Fosudo (2010) in Aina (2011: p.3) explained that:

The negative effects of poor reading skill can make a child develop a poor attitude toward school and can create self-esteem problems later in life. However, some problems attached to the poor reading habits includes; mass failure, poverty, loss of self esteem, and above all illiteracy. Also secondary school students must often associate reading with academic task and not for knowledge and pleasure: this does not enable the students who have the reading skill to maximize the activity for self and social development.

\section{Need for Effective Reading Habits}

The acquisition of reading skills has a beneficial effect on all school subject including social sciences, sciences, mathematics and so on. Poor reading skills can make a child develop a 
poor attitude toward school and can create self esteem problems later in life. Oke, (1996), gave reasons why people read to include: self-improvement, pleasure and a feeling of pride and prestige. Studies show a relationship between reading and early literacy and a child's emotional, mental health and social behavior. The study also showed that early in the primary grades, children who are struggling with illiteracy begin to experience failure and related negative effects in interpersonal skills. These effects can include task-avoidance and seeking of personal validation in venues that are antisocial. In Nigeria, a study carried out by Henry (2004) reveals that $40 \%$ of adult Nigerians never read a non-fiction book per year and only $1 \%$ that can successfully read one non-fiction book per month, The same study showed that 30 million Nigerians have graduated from high schools with poor reading habits. Some Nigerians may not read because they are not working in the right field. If regular reading is a required condition of your job, this effect means they would read, even if it is under duress. The magnitude of this problem jeopardizes the future of our public schools. What is most frustrating is that much of this reading problem can be prevented if government, libraries and teachers apply what is known as reading instruction or techniques. Okusaga (2008) asserts that being a former British colony, Nigeria's literacy culture ought to be standardized, as $99 \%$ of British citizens can read and write. The same cannot be said of Nigeria. Out of the 814 million illiterate people in the world, developing countries, Africa represent a huge percentage. However, Latin America, Asia and others are making frantic efforts to drastically reduce the illiteracy rate but the same cannot be said of Africa. However, efforts must be made to encourage and promote reading habits from an early age. This view is supported by Yusuf (2007), who says that children that imbibe good character during their formative years have developed good reading habit. This is often reinforced by the quality of teaching they have received in schools through their teachers who are the chief drivers of the education engine. They design the curriculum and the behavioral goals that are its products. Teachers should provide reading lists to accompany what is done in class and give assignments that will prompt students to read in the school or public library.

\section{Roles of Library in Promoting Reading Habits}

The need to promote effective reading habits among the general populace of Nigeria lies with school libraries and the National Library of Nigeria. The function of school libraries is to provide functional information services to students for the academic and information needs while the National Library of Nigeria helps the students with information materials after school. It's also the role of the National Library of Nigeria to conduct readership awareness campaign to the general public. The National Policy of Education (2004) has the following objectives as its strategies to improve the reading habits of Nigerians and this is to compliment the efforts of the National Library of Nigeria:

To promote the increase in production of reading materials in Nigeria, both in quality and variety

$>$ To encourage more reading Nigerians

Information Impact | Journal of Information and Knowledge Management 
To identify the major obstacles inhibiting reading in the country and finding ways of eliminating them.

The problem with the above objectives is that the readership promotion campaign by the National library is restricted largely to Abuja, Lagos and some few state capitals. The impact has not really been felt in other parts of the country because the National libraries had not been adequately funded to put the campaign in prints and electronic media. Libraries are integral part of the educational development of school children and youths. Without the support of efficient libraries, schools cannot successfully achieve the goals of education enumerated in the National Policy of Education which includes:

$>$ The inculcation of National consciousness and National unity

$>$ The inculcation of the right type of values and attitudes of the individual and the Nigeria society

$>$ The training of the mind in the understanding of the world around, and

$>$ The acquisition of appropriate skills, social abilities, competence and equipment for the individual to live and contribute to the development of the society.

Library provides access to reading materials through which school children and youths can gain and improve their skills. Libraries help introduce people to information for pleasure, passing examination, and personal growth through lifelong learning. Library provides materials that offer more extensive information than classroom study alone. Voluntary reading helps develop reading habits and mastery of languages, extends students' knowledge and assists them in their academic work. Students and youths who read are likely to have background knowledge, familiarity with new topics or subjects and thus find learning easier and interesting.

The role of libraries in promoting reading is crucial in developing scientific reflective thinking and creativity among young people. Libraries can help children and youths develop critical and independent thinking through their exposures to a wide variety of institution resources and learning opportunity. Also, there would be development of values, attitudes and appreciations. In the process of encouraging or inculcating the reading habits in children and youths, stakeholders should avoid nagging, bribing, judging, criticizing reading choices and setting unreasonable goals.

\section{Conclusion}

Education is a continuous process. It can be acquired formally through attendance at schools, workshops, seminars or other forms of training. Traveling had been recognized as an important form of education. People can become educated by traveling to lands far away from them through leisure reading and thereby learn about other people, their cultures and environment. A reading nation is an informed nation. Nigeria cannot be regarded as a reading nation because the lack of reading habits affects the younger generation of Nigerians performances at school and during examinations. Children and students with poor reading habits may engage in antisocial behaviors such as school violence, bullying, and examination 
malpractice. To redress this anomaly, several organizations and institutions are charged with the responsibility of acquiring and providing access to a variety of instructional and informationrich materials in different formats. The library continues to discharge this responsibility and employ other strategies that can promote reading culture. Other stakeholders like governments at different level, communities, organizations, parents and individual proprietors have their roles to play. All hands must be joined together to lift Nigeria from her present state to becoming a nation consisting of people with very high reading habits.

\section{Recommendations}

Having recognized that the there is poor reading habits among the Nigerian school children because of the poor school environment that does not provide them with a conducive environment for learning especially in inculcating good reading habits, and also the fact the there are no functional libraries stock with relevant materials both in the schools and public libraries that will help the children, this paper recommends the following to help in the educational life of the school children through a good reading habit:

1. All schools should have functional school libraries stocked with relevant reading materials that will help in improving the reading skills of children.

2. Local and state governments should provide functional public libraries that contain relevant literature that will help in inculcating good reading habits in young school children. These libraries should be found in all local governments' headquarters with mobile libraries to reach the nook and crannies of the state. This is to make information materials accessible to all school children.

3. The states Universal Basic Education and Ministries of Education should provide reading materials to all public schools. This is to help the underprivileged children have access to information which their parents cannot afford to buy for them.

4. Governments and school proprietors should recruit qualified English language teachers who will guide and mentor the children in the art of reading habits

5. Parents should also have influence in shaping and encouraging their children towards having purposeful reading habits. This is because peer groups and the social media seem to be having great influence in the lives of the youths which affects them negatively. This can only be erased by parents monitoring their wards and helping them have more time for their books.

6. Schools and parents should provide incentives to students as a motivator for encouraging them in developing good reading habits. 
Inculcating reading habits among Nigerian secondary schools students: the role of libraries

\section{References}

Bashir , I.\& Mattoo, N. H.(2012) A Study on Study Habits and Academic Performance Among Adolescents (14-19) years. International Journal of Social Science Tomorrow. 1(5).

Collins, M. and Cheek, E. (1999). Assessing and Guiding Reading Instruction, New York, McGraw Hill

Federal Republic of Nigeria (2004) National Policy on Education, 4th ed. Lagos: NERDC Press.

Fosudo, S. (2010). Reading as part to success" A Lecture delivered at the College Library Day, Adeniran Ogunsanya College of Education, Otto/Ijanikin, Lagos on February 24th. In Aina, A.J. (et al) "Poor Reading Habits among Nigerians: The Role of Libraries" Greene, B. (2001) "Testing Reading Comprehension of Theoretical Discourse with Close," Journal of Research in Reading. 24(1).

Henry, P. (2004). Children Reading Habits and their use of Media: Exhaustive Suggestions on Encouraging Reading Habits among Children. In Aina, A.J. (et al) "Poor Reading Habits among Nigerians: The Role of Libraries" (2011). Library Philosophy and Practice (ejournal). Paper 529. P.3

Ogunrombi, S.A \& Adio, G. (1995) "Factors affecting the reading habits of secondary school students", Library Review, 44(4).

Oke, E. (1996). Analysis of progress made by public libraries in Nigeria: Nigeria school library Journal 2(4)

Okebukola, F. O. (2004). Reading: Key to lifelong development. A key note address delivered at the workshop on readership promotion campaign organized by the National Library of Nigeria, Lagos

Okusaga, T.O. (2008). Development of school libraries for Effective Implementation of Universal Basic Education in Lagos in the 21 Century

Palani, K. K. (2012) Promising Reading Habits and Creating Literate Social. International Reference Research Journal Vol. III Issue 2(1) pp 91.

Rubin, D. (2002). Diagnosis and Correction in reading and guiding reading instruction. $4^{\text {th }}$ ed. Boston; Allyn and Bacon 
Yusuf, F. (2007). Repositioning school libraries in Nigeria: The catalyst for promoting reading habits among primary and secondary school students In Haliru, R.A. (et al) (2015) "An Assessment of Reading Habit among Secondary School Students in Kaduna Metropolis", IOSR Journal Of Humanities And Social Science (IOSR-JHSS) 20( 10), Ver. II (Oct. 2015).

Information Impact | Journal of Information and Knowledge Management 